\title{
The Agent of Virus Disease in Plants*
}

\author{
By Dr. John Caldwell
}

$\mathrm{M}^{\circ}$

OST of the detailed work on the nature of the virus agent has been carried out on the virus of the mosaic disease of tobacco. This virus is very easily obtainable in a fairly pure condition, is easily inoculable by rubbing virus preparations into healthy tissues and is resistant to storage and to chemical treatment. This resistance to ageing makes it possible to store the virus in vitro in powder form or in liquids over periods of years, and its presence as an active pathogen is easily demonstrable quantitatively as well as qualitatively by the use of the host-plant Nicotiana glutinosa, the leaves of which develop local lesions after being rubbed with virus material. It has long been known that there is a definite relationship between the number of lesions and the amount of virus present in the inoculum.

The most outstanding recent development in the study of the virus is the preparation by Stanley of a crystalline protein from the juice of plants infected with mosaic disease. The agent is separable from the erude, expressed plant juice by treatment with protein precipitants, and the virus has an intimate connexion, at the least, with the proteins of the tissues, as evidenced by the effect of pepsin in destroying the activity of the virus and by its antigenic reaction. While it has not yet been clearly demonstrated that the crystalline protein is, in fact, the virus agent in a pure state, Stanley's demonstration of the existence of the virus in the crystallizable protein fraction constitutes a step forward in the isolation of virus [see also p. 1051].

The study of the virus from the point of view of its possible protein nature is complicated by two main factors. It is apparently easily absorbed and inactivated by native proteins and, further, tests for virus activity must be carried out on host plants, since it is the pathogenic effect of the virus which ultimately demonstrates its presence in a given juice.

This biological test requires that, to demonstrate the activity of the virus, there be present no substance which prevents the entry into or subsequent increase of the virus in the host tissues. It has been shown that dead cells do not permit the entry into, or the movement of the virus in, the tissues, and absence of infection in the leaves of the test plant Nicotiana glutinosa, in some instances, may be due to the death of cells in the regions of inoculation and not to the absence of active virus. A test has recently been devised which makes it possible to distinguish between an inhibitory effect on the virus itself and a toxic effect on the tissues of the treated leaves. If the inhibitory substance be added in the same concentration to different concentrations of the virus material, that concentration not being too great to prevent lesion formation on the leaves of the host plant at some concentration of the virus, then the effect of the inhibitor will be different if it is acting on the virus, from its effect if the action be on the host tissues. If the action of the inhibitor be on the virus, then its effect will be most marked at the lower concentrations

* Based on a paper read on September 11 before Section K (Botany) of the British Association meeting at Blackpool. of virus and will be less obvious as the concentration increases until at high concentrations of virus it may not be demonstrable at all. If, on the other hand, the effect of the inhibitor is on the host tissues, the effect will be most marked at high concentrations of virus, when far fewer than the expected number of lesions will be formed, while at low concentrations of virus the effect of the inhibitor may not be demonstrable, since there are comparatively large numbers of possible points of entry of the virus.

The question of the entry of the virus into the tissues has received some attention recently. I demonstrated some time ago that it is possible to inject into the intercellular spaces of leaves large quantities of virus, to spray the leaves of a tomato or tobacco plant with virus material or to immerse the roots in virus juice without subsequent infection of the plant provided the tissues remain undamaged. It was concluded that virus is unable to enter an unbroken protoplast. This conclusion was challenged by Duggar, who reported that if tobacco virus No. 1 material was sprayed with an atomizer on to the leaves of tobacco plants, infection followed, in the course of a few days, entry of the virus being affected apparently through the stomata of the treated plants. In the light of these results, the work on the spraying of tobacco plants with virus material in an atomizer has been carefully repeated and it has been found that no infection was obtained under our conditions even after repeated spraying at three- or fourday intervals, when rigorous precautions were taken to prevent the rubbing of the leaves of the plants and special care was taken in watering them. All plants so sprayed and with one leaf lightly rubbed developed symptoms after only one spraying. This conclusion has been confirmed in a paper published last month by Dr. F. M. L. Sheffield at Rothamsted, whose experiments are reported to show "quite conclusively that the virus is unable to enter uninjured cells".

I have shown that the virus of tobacco mosaic does not travel across areas of dead cells but is confined to the living tissues, and that the weight of evidence suggests a fairly rapid passage along the protoplasmic strands between the cells. I have also shown that there is little evidence that the virus moves mechanically with the main food-streams. This conclusion has been questioned by various workers and further experiments have been carried out to examine this point. Experiments carried out in Exeter have shown that virus activity seems to be associated more with the activity of growing cells than with the movement of materials from the inoculated leaves. Three groups of tobacco plants were used in the experiments. One group was inoculated on the youngest available leaf, the second on a half-grown leaf and the third on the oldest leaf, all the plants being in the 4th-5th leaf stage. All the inoculated leaves were covered with tinfoil or black paper immediately on inoculation. Symptoms appeared first on the plants of the first group, then on most of the plants of the second group and rarely on the plants of the third group. The treated leaves of the first two groups of plants grew rapidly under 
the covers; while the adult leaves of the third group withered and died in the course of a week. It was evident that the virus could and did move rapidly out of the younger leaves, and that the movement of food materials into them had little effect on the movement of virus out of them.

The conclusion that the movement of the virus takes place along the protoplasmic strands was confirmed by the observation that the embryo of the seeds of infected tobacco and tomato plants has been shown by the work of myself and others to be healthy and to contain no virus. This may be due to the irregular distribution of virus in the plant tissues and to the absence of direct protoplasmic connexion between the embryo and the parent plant.

The conclusion that the protoplasmic strands are not the paths of movement has also been supported just recently by another paper of Dr. Sheffield, in whioh she shows that the guard cells of the stomata of Solanum nodiflorum do not contain inclusion bodies, while the epidermal cells of this plant on infection with tobacco mosaic virus develop very characteristic inclusion bodies. It has been possible to demonstrate the existence of protoplasmic strands between the epidermal cells of this plant and their complete absence between the guard cells and the neighbouring epidermal cells.

The work on the nature of the virus has opened up some interesting fields for further study. Evidence is being accumulated which indicates that the virus is protein in nature and that it can develop only in living tissues, with which it is intimately connected. This conclusion is of special interest when it is remembered that tobacco virus No. 1 has been shown to exist in some sixty strains, most of which are known to be mutually antagonistic in the plant.

\section{The Electrical Machinery Laboratory, Polytechnic, Regent Street, London}

$\mathrm{T}$ 'HE newly-equipped Electrical Machinery Laboratory at the Polytechnic, Regent Street, was formally opened on December 10, by Sir E. Henry Pelham, permanent secretary to the Board of Education. The occasion was the jubilee commemoration of the School of Engineering, which first provided an organized engineering training in 1886 .

A feature of interest at the meeting was the presence of all three heads of the School, Mr. H. J. Spooner, the first head, who retired in 1922, Prof. A. R. Horme, professor of mechanical engineering at the Heriot-Watt College, Edinburgh, who retired in 1929, and Mr. Philip Kemp, the present head.

The Electrical Machinery Laboratory was first equipped in 1911 when the Polytechnic was re-built, and the machines and apparatus then installed did good service both before and after the Great War. It was realized, however, that if instruction had to be given on up-to-date lines, a thorough re-organization was necessary, and accordingly, plans were prepared for a complete new equipment. The London County Council was approached for financial assistance and a very generous grant was made, enabling the work to be begun in 1933 .

The main supply to the Laboratory, which has an area of 4,800 sq. ft., is obtained from the Borough of St. Marylebone three-phase mains at a pressure of 416 volts and a frequency of 50 cycles per second. This is fed to three $20 \mathrm{kva}$. three-phase transformers in order to step the voltage down to 100 volts, which is the value chosen for the operation of the experimental plant. These three transformers can be operated singly or in parallel, and are each provided with an auxiliary boosting transformer for the purpose of maintaining a constant voltage on the experimental circuits. This voltage is ultimately maintained at a constant value by means of an automatic voltage regulator.

Direct current supplies are obtained from two $15 \mathrm{kw}$. rotary converters, each with its own transformer. A 540 ampere-hour secondary battery is also available for D.c. work demanding a steady voltage. This battery is connected to the main D.c. bus bars, but has its own separate charging plant.
The experimental D.C. supply is taken to a special distribution board, before going away to the various experimental circuits.

The whole of the A.c. experimental supply is brought to a large plug board enabling single-phase or three-phase supply to be delivered to any of the experimental machines at will. If necessary, a particular circuit can be fed from one particular transformer, which can be isolated for the purpose. Signal lights are provided at various points to in. dicate live circuits.

Instead of using the transformers directly, alternative 100 volt A.c. supplies can be obtained from four $3 \mathrm{kva}$. three-phase alternators, these also being connected to the main plug board. Two of these alternators are separately driven by two threephase synchronous motors, a third by a three-phase commutator motor of the Schrage type, whilst the remaining alternator is driven by a D.c. motor.

A feature of the laboratory is the large-scale diagram printed on the wall, showing the whole of the experimental supply circuits.

The four motor-alternator sets mentioned above can be used for experimental purposes as well as for supplying other machines. The synchronous motors of the first two have their stators mounted on a rack and pinion, for the study of load conditions, and they are also each provided with a Joubert contact equipment for wave form investigations.

The D.c. testing plant consists of two 3-h.p. shunt motors, two 3-h.p. series motors and two $3 \mathrm{kw}$. motor-generator sets, the motors of which can be uncoupled at will.

Converting plant is represented by a $3 \mathrm{kw}$. threephase rotary converter and a $3 \mathrm{kw}$. six-phase rotary converter direct coupled to a 3-h.p. three-phase induction motor, so that the comkination can be run as a motor-converter if required. Both these sets are provided with Joubert contacts for wave form work.

Two mercury arc rectifiers are also installed, one being a $3 \mathrm{kw}$. single phase unit, whilst the other is a $3 \mathrm{kw}$. six-phase rectifier with grid control.

Alternating current motors are represented by two three-phase induction motors of 2 h.p. and 3 h.p. 